\title{
Extractive Spectroscopic Determination of Lansoprazole in Pharmaceutical Dosage Form
}

\author{
IFFATH RIZWANA $^{1}$, K. VANITHA PRAKASH ${ }^{2 *}$ and G. KRISHNA MOHAN ${ }^{3}$ \\ ${ }^{1}$ Research and Development, \\ JNTU-K, Kakinada, A.P. India and Deccan School of Pharmacy, Hyderabad, AP, India \\ ${ }^{2}$ Department of Pharmaceutical Analysis, \\ SSJ College of Pharmacy, Gandipet, Hyderabad, A.P. India \\ ${ }^{3}$ Centre for Pharmaceutical Sciences, IST, JNTU Hyderabad, A.P. India \\ vanithaprakashssj@gmail.com; prakash.karanam@gmail.com
}

Received 18 August 2014 / Accepted 5 September 2014

\begin{abstract}
Two simple and sensitive extractive spectrophotometric methods have been described for the assay of Lansoprazole (LPZ) either in pure form or in pharmaceutical formulations. The methods were based on the formation of ion-pair complex between LPZ and Metanil Yellow (MY) - MethodA and methyl orange (MO)- Method- B, at $\mathrm{pH} 2.5$ has been described. The formed complex were extracted quantitatively into chloroform and measured at $440 \mathrm{~nm}$ and $450 \mathrm{~nm}$ with MY and MO respectively. Beer's law was obeyed in the concentration range of $20-70 \mu \mathrm{g} \mathrm{mL}^{-1}$ and $6-16 \mu \mathrm{g} \mathrm{mL}^{-1}$ with molar absorptivity of $1.329 \times 10^{-8}$ and $1.822 \times 10^{-8} \mathrm{~L} \mathrm{~mol}^{-1} \mathrm{~cm}^{-1}$ with MY and MO respectively. Statistical comparison of the results of the proposed method with those of the reference method shows excellent agreement and indicates no significant difference in accuracy and precision. The limits of detection and quantification have been determined for two methods. Both the methods have been validated as per the guidelines of $\mathrm{ICH}$. The methods have been applied to the determination of drug in commercial capsules and results of analysis were validated statistically through recovery studies
\end{abstract}

Keywords: Extractive spectrophotometric, Lansoprazole, Metanil Yellow, Methyl Orange.

\section{Introduction}

Lansoprazole (RS)- 2- ([3- methyl- 4- (2,2,2- trifluoroethoxy)pyridin-2- yl]methyl sulfinyl)$1 H$ - benzo[d] imidazol (Figure 1 ) is a substituted benzimidazole compound and it is a proton pump inhibitor ${ }^{1}$, widely used as an antiulcer drug in the treatment and maintenance of healing of duodenal or gastric ulcers, erosive and reflux esophagitis. It is official in USP, The characteristic properties of LPZ are due to its secondary and tertiary amino groups and sulphoxide grouping ${ }^{2}$.

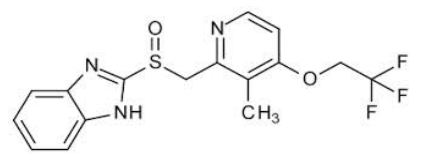

Figure 1. Chemical structure of Lansoprazole 
LPZ has a greater inhibitory effect on $H$. pylori than omeprazole, and is thus widely used in the treatment of benign gastric ulcer associated with $H$. pylori; duodenal ulcer and reflux oesophagatis. LPZ is also indicated for Zollinger-Ellison Syndrome and acid related Dyspepsia. The therapeutic importance of LPZ justifies research to develop analytical methods for its determination in body fluids and in pharmaceuticals.

Because of simplicity, reasonable accuracy and precision, speed and sensitivity, visible spectrophotometry has withstood the test of time and remained competitive with the newer analytical methods. Literature survey revealed that the only visible spectrophotometric method $^{3}$ reported is based on the formation of a blue chromogen measurable at $810 \mathrm{~nm}$ when LPZ was reacted with iron(III) chloride and ferricyanide in $\mathrm{HCl}$ medium. Few more methods such as HPLC $^{4-6}$, HPTLC $^{7}$, LC-MS-MS ${ }^{8,9}$, Tirimetric ${ }^{10-12,}$ UV spectrophotometry ${ }^{13,14}$ and visible spectrophotometry ${ }^{15}$, relatively little attention was paid to the development of visible spectrophotometric methods for this drug.

The present investigation aims to develop sensitive and cost-effective methods for the determination of LPZ in pure form and in tablet dosage form by extractive visible spectrophotometry. The methods utilize Metanil Yellow (MY) - Method- A and Methyl Orange (MO)- Method- B as reagents. The methods have the advantages of speed and simplicity besides being accurate and precise, and can be adopted by the pharmaceutical laboratories for industrial quality control.

\section{Experimental}

\section{Instrument}

Electronic Weighing balance - (Single pan balance, Model Axis LC/GC), Digital pH meter (Model- Systronics), Sonicator- Ultra Sonicator (Model- Bandelin sonorex), Double beam UV-Visible spectrophotometer - Schimadzu 1800. UV spectra of standard and sample solutions were recorded in $1 \mathrm{~cm}$ quartz cells at the wavelength ranges of $200-400 \mathrm{~nm}$.

\section{Chemicals and Reagents}

Lansoprazole (LPZ) was obtained as a gift sample from Hetero drugs Pvt. Ltd, Hyderabad, India. Metanil yellow (MY) and methyl orange (MO) was purchased from Merck, Mumbai. Chloroform, potassium dihydrogen phosphate was purchased from SD Fine chem, Mumbai. Distilled water was prepared in house. All other chemicals used were AR grade.

\section{Preparations of Buffer and Reagents}

\section{Preparation of phosphate buffer of $\mathrm{pH} 2.5$}

$100 \mathrm{~g}$ of potassium dihydrogen phosphate was dissolved in $800 \mathrm{~mL}$ of water; $\mathrm{pH}$ of the resulting solution was adjusted to 2.5 with dilute hydrochloric acid. The final volume was made to $1000 \mathrm{~mL}$ with distilled water.

\section{Preparation of standard stock solution}

A standard stock solution of LPZ was prepared by dissolving $100 \mathrm{mg}$ of it in methanol in a $100 \mathrm{~mL}$ volumetric flask, the final volume was made upto the mark with the same to get the final concentration of $1 \mathrm{mg} / \mathrm{mL}$.

\section{Preparation of working standard solution}

A working standard solution containing $100 \mu \mathrm{g} / \mathrm{mL}$ was prepared by diluting the above stock solution. The fresh working standards were prepared dialy. 


\section{Determination of $\lambda_{\text {max }}$}

Method A: with metanil yellow (MY)

In a $25 \mathrm{~mL}$ separating funnel, $1 \mathrm{~mL}$ of working standard of the drug was taken, $2 \mathrm{~mL}$ phosphate buffer $\mathrm{pH} 2.5,5 \mathrm{~mL}$ of chloroform and $2 \mathrm{~mL}$ of $0.4 \%$ MY was added, stirred vigorously, and the chloroform layer was separated carefully. A light orange colored complex was observed. The resulted solution was scanned for the determination of $\lambda_{\max }$ in the visible range of $400-800 \mathrm{~nm}$.

\section{Method B: With methyl orange (MO)}

In a $25 \mathrm{~mL}$ separating funnel, $1 \mathrm{~mL}$ of working standard of the drug was taken, $2 \mathrm{~mL}$ phosphate buffer $\mathrm{pH} 2.5,5 \mathrm{~mL}$ of chloroform and $2 \mathrm{~mL}$ of $0.2 \% \mathrm{MO}$ was added, stirred vigorously, and the chloroform layer was separated carefully. A light yellow colored complex was observed. The resulted solution was scanned for the determination of $\lambda_{\max }$ in the visible range of 400-800 $\mathrm{nm}$.

\section{Preparation of sample solution (for assay of lansoprazole capsules)}

Lansoprazole (PREVACID novartis), containing $15 \mathrm{mg}$ were successfully analyzed by the proposed methods. 10 capsules of Prevacid were accurately weighed and powdered. Tablet powder equivalent to $100 \mathrm{mg}$ of LPZ was dissolved in $100 \mathrm{~mL}$ of ethanol in a $100 \mathrm{~mL}$ volumetric flask and filtered. The solution was suitably diluted and analysed employing the procedures given under the procedure for bulk samples. None of the excipients usually employed in the formulation of capsules interfered in the analysis of LPZ by the proposed methods. A summary of results of both the methods were shown in Table 1.

Table 1. Summary of Validation results of Method A and B

\begin{tabular}{lcc}
\hline \multirow{2}{*}{ Parameters } & \multicolumn{2}{c}{ Results } \\
\cline { 2 - 3 } & Method $-\mathrm{I}$ & Method-II \\
\hline Lamda max $(\chi \mathrm{max})^{*}$ & $440 \mathrm{~nm}$ & $450 \mathrm{~nm}$ \\
Beer's law limits $(\mu \mathrm{g} / \mathrm{mL})$ & $20-70$ & $6-16$ \\
Molar & $1.329 \times 10^{-8}$ & $1.822 \times 10^{-8}$ \\
Sandell's sensitivity & 0.101 & 0.014 \\
Regression equation & $\mathrm{Y}=0.012 \mathrm{x}+0.119$ & $\mathrm{Y}=0.055 \mathrm{x}$ \\
Slope $(\mathrm{m})$ & 0.012 & $0.055 \mathrm{x}$ \\
Intercept(c) & 0.119 & 0 \\
Correlation coefficient $(\mathrm{r} 2)$ & 0.998 & 0.999 \\
Precision $(\% \mathrm{RSD}){ }^{* *}$ & 0.484 & 0.2935 \\
LOD $(\mu \mathrm{g} / \mathrm{mL})$ & 0.903 & 0.254 \\
LOQ $(\mu \mathrm{g} / \mathrm{mL})$ & 2.738 & 0.77 \\
Assay $\left(\%\right.$ Purity) ${ }^{* *}$ & 100.06 & 100 \\
\hline \multicolumn{2}{c}{${ }^{*}$ Average of 6 replicate samples; ${ }^{* *}$ Average of 3 replicate samples }
\end{tabular}

\section{Results and Discussions}

\section{Method A (with MY)}

LPZ was found to react with MY under the experimental conditions to form a light orange colored complex exhibiting $\lambda_{\max }$ at $440 \mathrm{~nm}$. The $\lambda_{\max }$ curve was shown in Figure 2.

Method B (with MO)

LPZ was found to react with MO under the experimental conditions to form Light yellow colored complex, exhibiting $\lambda_{\max }$ at $450 \mathrm{~nm}$. The $\lambda_{\max }$ curve was shown in Figure 3. 


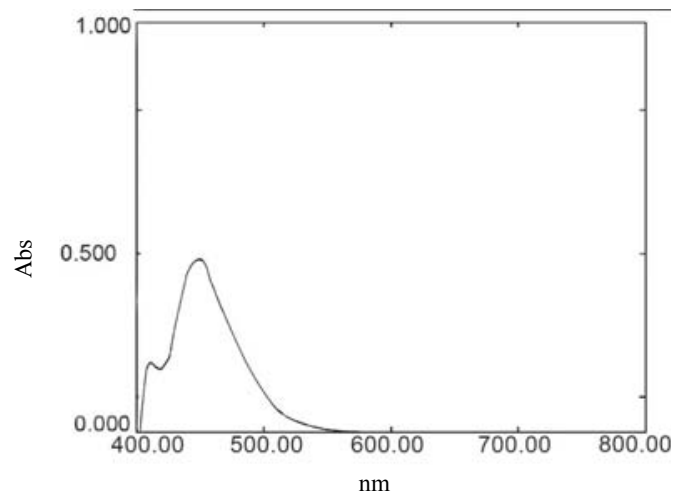

Figure 2. The $\lambda_{\max }$ curve of LPZ with MY

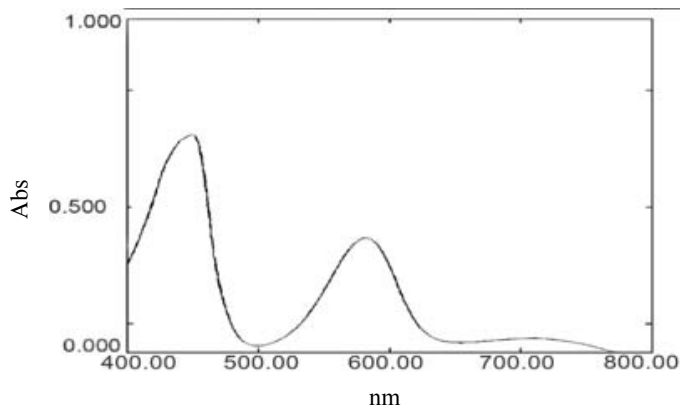

Figure 3. The $\lambda_{\max }$ curve of LPZ with MO

\section{Validation of the proposed method}

\section{Linearity and sensitivity}

Calibration curves for methods $\mathrm{A}$ and $\mathrm{B}$ in the ranges $20-70 \mu \mathrm{g} / \mathrm{mL}$ and $6-16 \mu \mathrm{g} / \mathrm{mL}$ were linear with correlation coefficients (r2) of 0.9989 and 0.9993 for methods A and B, respectively. The molar absorptivities $(\Sigma)$ at $440 \mathrm{~nm}$ and $450 \mathrm{~nm}$ for methods A and B were $1.329 \times 10^{-8}$ and $1.822 \times 10^{-8} \mathrm{~L} / \mathrm{mole} / \mathrm{cm}$, respectively. The Sandell's sensitivity values were 0.101 and 0.014 for methods $\mathrm{A}$ and $\mathrm{B}$ respectively. The calibration curves of method $\mathrm{A}$ and B were shown in Figure 4 and 5 respectively.

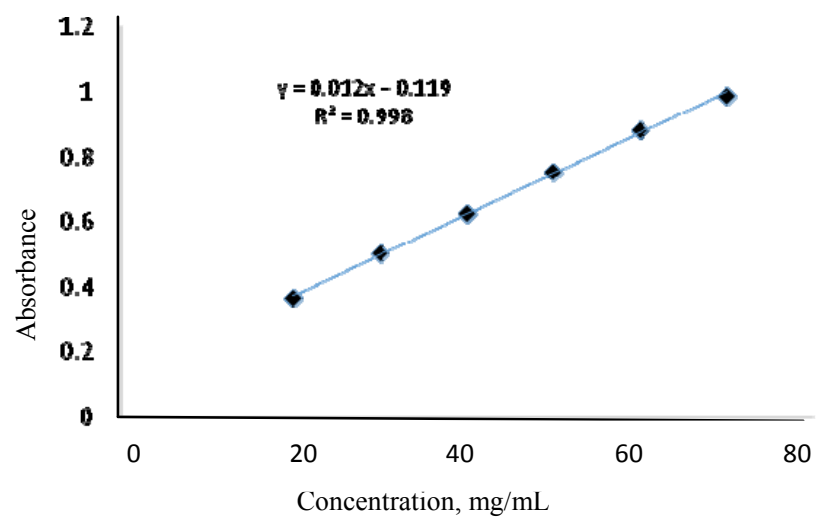

Figure 4. Linearity cuvre of LPZ with MY (Method A) 


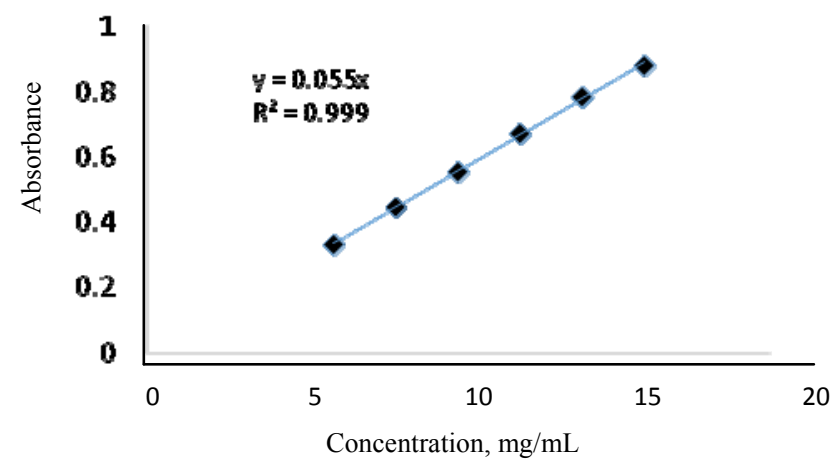

Figure 5. Linearity cuvre of LPZ with MO (Method B)

\section{LOD and LOQ}

The limit of detection (LOD) is defined as the minimum level at which the analyte can be reliably detected for the two methods was calculated using the following equation

\section{$\mathrm{LOD}=3.3 \times$ Standard deviation / Slope}

In accordance with the formula, the detection limits were found to be 0.903 and 0.254 $\mu \mathrm{g} / \mathrm{mL}$ for method A and B, respectively. The limit of quantification (LOQ) is defined as the lowest concentration that can be measured with acceptable accuracy and precision

$$
\text { LOQ }=10 \times \text { Standard deviation / Slope }
$$

According to this equation, the limit of quantification was found to be 2.738 and 0.77 $\mu \mathrm{g} / \mathrm{mL}$ for Method A and B respectively; the summary of validation parameters for the two methods is given in Table 1.

\section{Accuracy and precision}

The accuracy and precision of the proposed method were determined at three concentration levels of LPZ (within the linear range) by analyzing three replicate analyses on pure drug of each concentration. The percentage relative error as accuracy and percentage relative standard deviations (RSD) as precision for the results did not exceed $2 \%$ for the two methods as shown in Table 1, indicating the good reproducibility and repeatability of the two methods. This good level of precision and accuracy was suitable for quality control analysis of LPZ in their pharmaceutical formulation.

\section{Application of the methods}

The proposed methods were applied to the pharmaceutical formulation containing LPZ. The results are shown in Table 1 indicate the high accuracy of the proposed methods for the determination of the studied drug. The proposed methods have the advantage of being virtually free from interferences by excipients. The mean percentage purities were $100.06 \pm$ 0.24 and $100.00 \pm 0.26$ for method $\mathrm{A}$ and $\mathrm{B}$, respectively (Table 1).

\section{Conclusion}

The development visible spectrophotometric methods for the determination of LPZ in pharmaceutical formulation were simple, sensitive, rapid and accurate. These methods were practical and valuable for routine application in quality control laboratories for analysis of LPZ. 


\section{Acknowledgement}

The authors are thankful to M/s. Hetero Drugs Pvt. Ltd, Hyderabad, for providing pure drug sample and to the management and principal of Deccan School of Pharmacy, Hyderabad, A.P India, for providing laboratory facilities.

\section{References}

1. Sweetman S C and Martindale, The Complete Drug Reference, $34^{\text {th }}$ Ed., London, Pharmaceutical Press, 2005, 1269-1270.

2. Keith G T, Gastrointestinal and liver drugs, In: Gennaro A R, Editor Remington, The Science and Practice of Pharmacy, $20^{\text {th }}$ Edn., Vol. I, Maryland: Lippincott Williams and Wilkins, 2000, 1226.

3. Kanakapura Basavaiah, Veeraiah Ramakrishna, Urdigere Kumar, Acta Pharmaceutica, 2007, 57(2), 211-220; DOI:10.2478/v10007-007-0017-5

4. Unoa T, Yasui FN, Takahata T, Sugawara K, Tateishi T, J Chromatogr B: Anal Technol Biomed Life Sci., 2005; 816, 309.

5. Avgerinos A, Karidas T, Potsides C and Axarlis S, Eur J Drug Metab Pharmacokinet., 1998, 23(2), 329-332; DOI:10.1007/BF03189359

6. Basavaiah K, Ramakrishna V, Anil Kumar U R and Udaykumar, Indian J Chem Technol., 2006, 13, 549-554.

7. Pandya K K, Mody V D, Satia M C, Mody A, Mody R K and Chakravarthy B K, $J$ Chromotoqr B: Biomed Sci Appl., 1997, 693, 199.

8. Celso H O, Barrientos-Astagarragab R E, Eduardo A, Mendesb G D, Débora R da S and Gilberto de N, J Chromatogr B, 2003, 783(2), 453-459; DOI:10.1016/S15700232(02)00711-0

9. Basavaiah K and Prameela H C, Science Asia, 2003, 29, 147-153.

10. Basavaiah K and Prameela H C, Bioanal Chem., 2003, 376(6), 879-883.

11. Basavaiah K and Chandrashekar U, Acta Ciencia Indica Chem., 2003, 29, 25.

12. Basavaiah $\mathrm{K}$ and Nagegowda P, IL Farmaco, 2004, 59(2), 147-153; DOI:10.1016/j.farmac.2003.11.012

13. Puratchikodi A, Krishnamoorthy G, Joykat B and Valarmathy R, Eastern Pharma., 1996, 43, 446.

14. Al-Zehouri H I, El-Subbaghand Abdullah A. Al-Badr, Analytical Profiles of Drug Substances and Excipients Volume 2001;28:117-15 J, Department of Pharmaceutical Chemistry, College of Pharmacy King Saud University.

15. Basavaiah K, Ramakrishna V, Anil Kumar U R and Udaykumar, Indian J Chem Technol., 2006, 549-554. 